Article

\title{
Impact of Halogen Substituents on Interactions between 2-Phenyl-2,3-dihydroqulinazolin-4(1H)-one Derivatives and Human Serum Albumin
}

\author{
Feng Liu, Yi Wang, Cong Lv, Lei Wang, Junjun Ou, Min Wang and Shangzhong Liu * \\ Department of Applied Chemistry, China Agricultural University, Beijing 100193, China \\ * Author to whom correspondence should be addressed; E-Mail: shangzho@cau.edu.cn; \\ Tel.: +86-10-6273-1070; Fax: +86-10-6273-1070.
}

Received: 16 December 2011; in revised form: 26 January 2012 / Accepted: 27 January 2012 / Published: 17 February 2012

\begin{abstract}
A novel type of 2-(un)substituted phenyl-2,3-dihydroquinazolin-4(1H)-one (DQL) derivatives were designed and synthesized to study the impact of halogen substituents on interactions between DQL and human serum albumin (HSA) by comparison methodology. The interactions between DQL and HSA were studied by fluorescence spectroscopy. The intrinsic fluorescence of human serum albumin was quenched by DQL through a static quenching mechanism. Site marker competitive experiments showed that DQL bound to HSA in site II (subdomain IIIA). The binding constants, the numbers of binding sites and the thermodynamic parameters were measured too. The results indicated that the interactions were spontaneous, mainly through hydrophobic forces, and the substitution by halogen atoms in the benzene ring could increase the interactions between DQL and HSA. Furthermore, the binding affinity was enhanced gradually with the increasing of halogen atomic number.
\end{abstract}

Keywords: synthesis; fluorescence spectroscopy; human serum albumin (HSA); DQL

\section{Introduction}

Human serum albumin (HSA), the most abundant protein in the circulatory system, has many physiological and pharmacological functions. It is chiefly responsible for the maintenance of blood $\mathrm{pH}$ and contributes to colloid osmotic blood pressure. Moreover, it provides a depot and carrier for many endogenous and exogenous ligands present in blood. It plays a prevailing role in drug pharmacokinetics 
and pharmacodynamics due to its capacity to bind a large variety of drugs [1-3]. The binding affinities of drugs to HSA can strongly affect their absorption, distribution, metabolism, excretion, and their therapeutic effects. Generally, strong binding can decrease the concentrations of free drug in plasma, while weak binding can lead to short lifetime and/or poor distribution. For example, many promising new drugs were rendered ineffective due to their unusually high binding affinity to HSA [4-7]. Therefore, it is important to investigate the interactions between new compounds and HSA in the early process of drug discovery $[8,9]$.

Heterocyclic structures form the basis of many pharmaceutical, agrochemical and veterinary products. Quinazolines are one of the most important classes of heterocyclic compounds, and many quinazoline derivatives have been reported to possess anticancer, antitubercular, antibacterial, antifungal, anti-HIV, analgesic, anti-inflammatory, anticonvulsant, antiparkinson, anti-histaminic, anthelmintic, and antihypertensive activities [10-18]. Thus, considerable attention has been focused by biologists and chemists on their structures and bioactivity. However, scarce information is available on the interactions of this class of compounds with serum albumin; especially, no information is available on the impact of halogen substituents on the interactions between quinazoline derivatives and serum albumin.

In this paper, we designed and synthesized a new type of 2-(un)substituted phenyl-2,3-dihydroquinazolin $-4(1 H)$-one (DQL) derivatives using the synthetic route shown in Scheme 1, and investigated the binding interactions between five DQLs and HSA at three temperatures by fluorescence spectroscopy. The binding mechanisms and the binding parameters of five DQL with HSA such as binding constants, binding sites, and binding modes have been discussed. The influence of halogen substituent on DQL-HSA interactions was studied under simulated physiological conditions using 2-phenyl-2,3dihydroquinazolin- $4(1 H)$-one as reference compound. The results provide a quantitative understanding of halogen substituent effects on DQL-HSA interactions to some extent, which could be useful for further design of potential biologically active substituted quinazolinone derivatives.

Scheme 1. Synthetic route to the title compounds.<smiles>[R]c1ccc(/C=N/N2C(=O)c3cc(Cl)ccc3NC2c2ccc([R])cc2)cc1</smiles><smiles>[R]c1ccc(/C=N/N2C(=O)c3cc(Cl)ccc3N(C(=O)CC(C)(C)C)C2c2ccc([R])cc2)cc1</smiles> 


\section{Results and Discussion}

\subsection{Synthesis}

A number of quinazoline derivatives were designed and synthesized in our laboratory for discovering new biological molecules based upon on this versatile skeleton, and the introduction of $t$-butylacetyl moieties on quinazolines was found to improve their binding to HSA to some extent through hydrophobic action. Thus, we designed and synthesized compounds 3a-e to study the impact of halogen substituents on the interactions of HSA and quinazolines.

\subsection{Fluorescence Quenching Mechanism}

A variety of molecular interactions can result in quenching of compound fluorescence. These include ground-state complex formation, collisional quenching, excited state reactions, molecular rearrangement, and energy transfer with two classes of dynamic and static quenching. Dynamic and static quenching can be distinguished by their different dependence on temperature and viscosity, or preferably by lifetime measurements [19]. To confirm the mechanism of quenching fluorescence of HSA by DQL, the Stern-Volmer equations (1) and (2) [20] were used for static and dynamic quenching to analyze obtained data:

$$
\begin{gathered}
F_{0} / F=1+K_{\mathrm{SV}}[\mathrm{Q}] \\
F_{0} / F=1+K q \tau_{0}[\mathrm{Q}]
\end{gathered}
$$

where $F_{0}$ and $F$ are the fluorescence intensities of HSA in the absence and presence of the quencher, respectively, $K_{\mathrm{SV}}$ is the Stern-Volmer quenching constant, $K q$ is the bimolecular quenching constant, $\tau_{0}$ is the average lifetime of the biomolecule without the quencher $\left(\tau_{0}=10^{-8} \mathrm{~S}^{-1}\right)$ [21], and [Q] is the concentration of the quencher. Figure 1 displays the Stern-Volmer plots at $298 \mathrm{~K}$ and different quencher concentrations. All Stern-Volmer plot curves were found to be linear with high values, and the calculated $K_{\mathrm{SV}}$ and $K q$ at the corresponding temperatures were listed in Table 1.

Figure 1. Stern-Volmer plots for DQL with HSA at $298 \mathrm{~K}$.

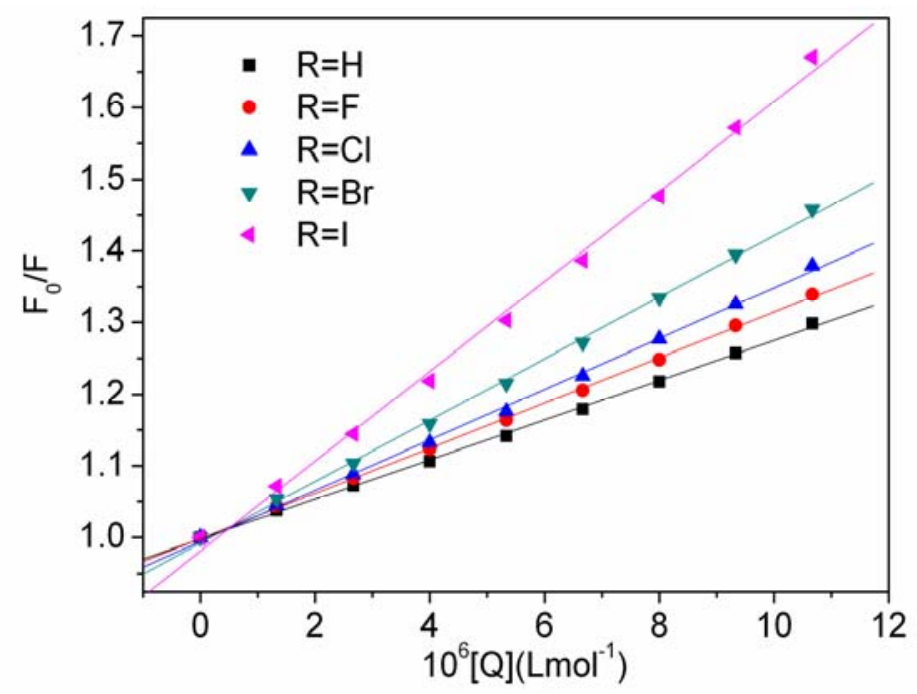


Table 1. Stern-Volmer quenching constants for the interactions of DQL with HSA at different temperatures.

\begin{tabular}{lccccc}
\hline $\mathbf{C o m p o u n d}$ & $\mathbf{T}(\mathbf{K})$ & $\boldsymbol{K}_{\mathbf{S v}}\left(\times \mathbf{1 0}^{\mathbf{4}} \mathbf{M}^{-\mathbf{1}}\right)$ & $\boldsymbol{K q}\left(\times \mathbf{1 0}^{\mathbf{1 2}} \mathbf{M}^{\mathbf{- 1}} \mathbf{s}^{-\mathbf{1}}\right)$ & $\boldsymbol{R}^{\mathbf{a}}$ & $\boldsymbol{S D}^{\mathbf{b}}$ \\
\hline $\mathbf{R}=\mathbf{H}$ & 298 & 2.77 & 2.77 & 0.99956 & 0.00322 \\
& 307 & 2.98 & 2.98 & 0.99933 & 0.00424 \\
& 316 & 3.23 & 3.23 & 0.99919 & 0.00513 \\
& 298 & 3.14 & 3.14 & 0.99975 & 0.00274 \\
$\mathbf{R}=\mathbf{F}$ & 307 & 3.41 & 3.41 & 0.99955 & 0.00398 \\
& 316 & 3.52 & 3.52 & 0.99925 & 0.00534 \\
& 298 & 3.54 & 3.54 & 0.99932 & 0.00510 \\
$\mathbf{R}=\mathbf{C l}$ & 307 & 3.64 & 3.64 & 0.99952 & 0.00442 \\
& 316 & 3.82 & 3.82 & 0.99899 & 0.00672 \\
& 298 & 4.29 & 4.29 & 0.99934 & 0.00610 \\
$\mathbf{R}=\mathbf{B r}$ & 307 & 4.41 & 4.41 & 0.99905 & 0.00751 \\
& 316 & 4.47 & 4.47 & 0.99923 & 0.00686 \\
& 298 & 6.27 & 6.27 & 0.99837 & 0.01397 \\
$\mathbf{R}=\mathbf{I}$ & 307 & 6.32 & 6.32 & 0.99771 & 0.01675 \\
& 316 & 6.62 & 6.62 & 0.99809 & 0.01600 \\
\hline
\end{tabular}

${ }^{\mathrm{a}} R$ is the correlation coefficient. ${ }^{\mathrm{b}} \mathrm{S} D$ is the standard deviation for the $K_{\mathrm{SV}}$ values.

It is known that linear Stern-Volmer plots indicate only one type of quenching mechanism, either static or dynamic, being predominant [22]. The plots showed that $K_{\mathrm{SV}}$ and $\mathrm{Kq}$ increased as the temperature increased, which indicated that the mechanism of the quenching may be a dynamic quenching. However, the values of $\mathrm{Kq}$ for all reactions of DQL-HSA in Table 1 fell in the range of $2.77 \times 10^{12}$ to $6.62 \times 10^{12} \mathrm{~mol} \cdot \mathrm{L}^{-1}$, and were much higher than $2.0 \times 10^{10} \mathrm{~mol} \cdot \mathrm{L}^{-1}$, the maximum scatter collision quenching constant of various quenchers with biopolymer [23]. Hence, it could be proposed that the quenching mechanism was not initiated by dynamic collision but rather originated from the formation of a complex through a static quenching procedure.

Furthermore, the effect of DQL on the fluorescence emission spectra of HSA in Figure 2 showed that the fluorescence intensity of HSA consistently decreased in the presence of increasing concentration of DQL, and a slight red shift at the maximum emission wavelength of HSA was observed. The latter indicated again that the complex between DQL and HSA formed [24]. Therefore, we conclude here the responsibility of static quenching mechanism as the dominant mechanism of the HSA fluorescence quenching by DQL.

For a complex formation process, a modified Stern-Volmer Equation (3) was used to calculate the affinity constant $K_{\mathrm{a}}$ of the binding between DQL and HSA [25,26]:

$$
F_{0} /\left(F_{0}-F\right)=f_{\mathrm{a}}^{-1} \cdot K_{\mathrm{a}}^{-1} \cdot[\mathrm{Q}]^{-1}+f_{\mathrm{a}}^{-1}
$$

where $f_{\mathrm{a}}$ represents the fraction of accessible fluorescence and $K_{\mathrm{a}}$ is the effective quenching constant. $F_{0} /\left(F_{0}-F\right)$ is linear with the reciprocal value of the quencher concentration [Q], and the slope equals the value of $f_{\mathrm{a}}^{-1} \cdot K_{\mathrm{a}}^{-1}$. Data were treated according to the modified Stern-Volmer equation to obtain the linear plots at different temperatures shown in Figure 3. The corresponding values of $K_{\mathrm{a}}$ in Table 2 showed that the affinity constants all increased after substitution by halogen atoms in benzene ring. 
Figure 2. The fluorescence quenching spectra of HSA at different concentrations of DQL at $298 \mathrm{~K}$.
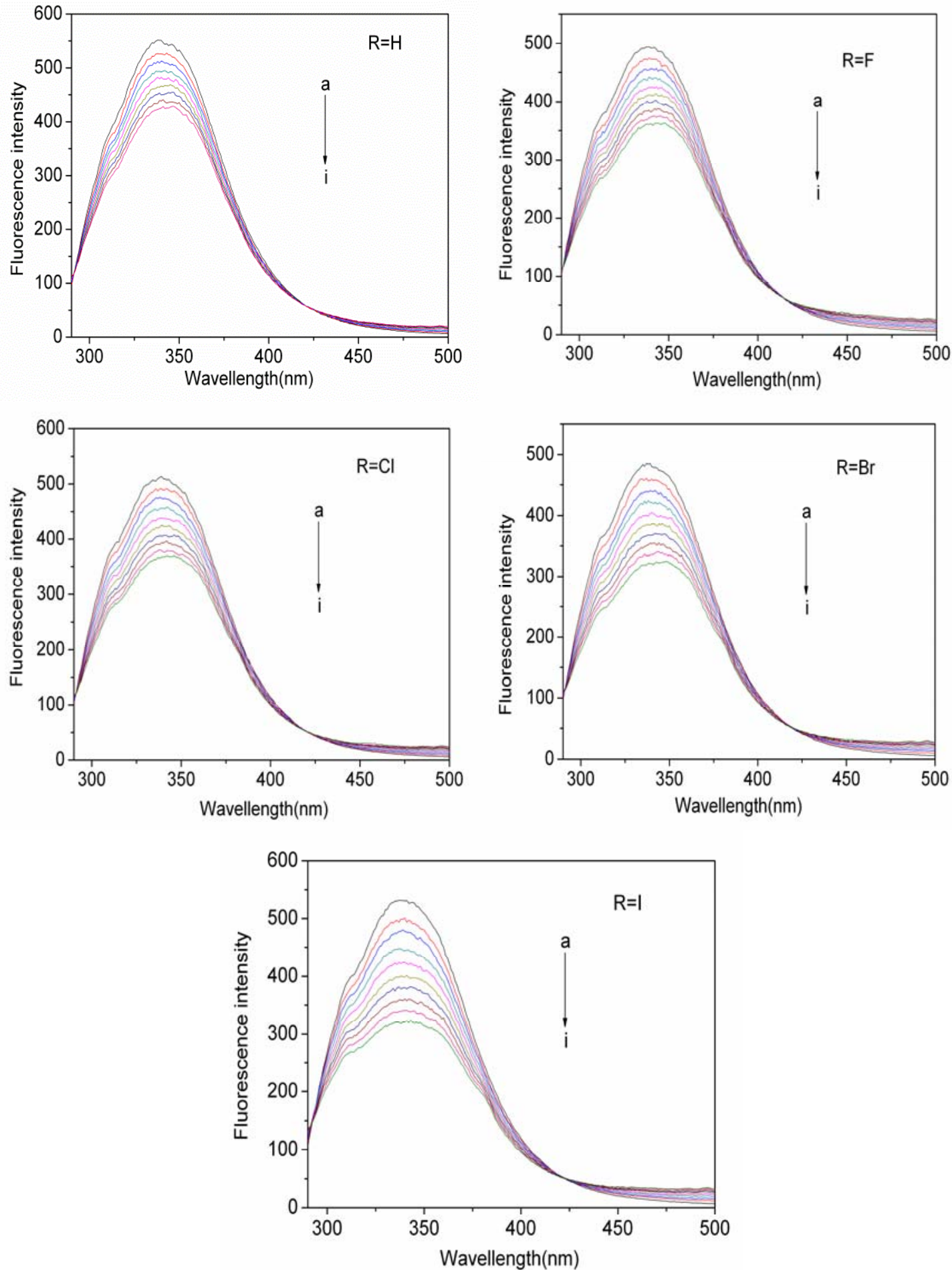

The quenching experiments of various DQL's were conducted at $\lambda_{\mathrm{ex}}=280 \mathrm{~nm}$ with the concentration of HAS $\left(1.0 \times 10^{-6} \mathrm{M}\right)$ and the concentrations $(0.000,1.333,2.667,4.000,5.333$, $6.667,8.000,9.333$, and 10.667 to a-i, respectively) of DQL $\left(\times 10^{-6} \mathrm{M}\right)$. 
Figure 3. Modified Stern-Volmer plots of DQL-HSA systems.
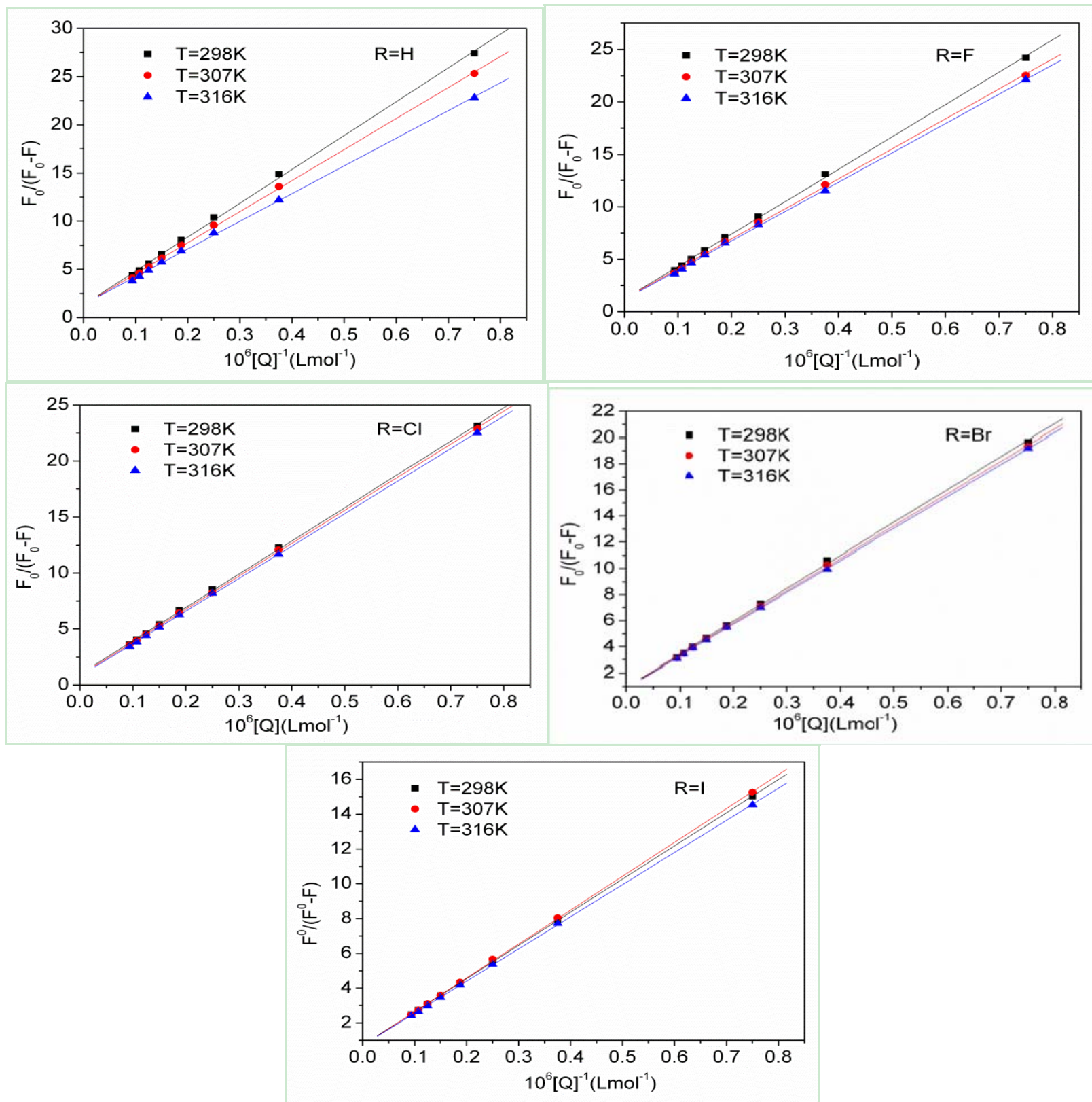

\subsection{Binding Sites and Identification of Binding Sites on HSA}

For a complex formation process, the number of binding sites can be determined according to the double-logarithmic equation [27,28]:

$$
\lg \left[\left(F_{0}-F\right) / F\right]=\lg K_{\mathrm{b}}+n \lg [\mathrm{Q}]
$$

where $F_{0}$ and $F$ are the fluorescence intensities in the absence and presence of the ligand, and $K_{\mathrm{b}}$ and $\mathrm{n}$ are the binding constant and the number of binding sites, respectively. According to equation (4), a plot of $\log \left[\left(F_{0}-F\right) / F\right]$ versus $\log [\mathrm{Q}]$ will produce a straight line whose slope is equal to the number of binding sites. The data shown in Table 3 demonstrated a good linear relationship and values of $n$ approximately equal to 1 , which indicated that there was only one molecule of DQL binding to one molecule of HSA. 
Table 2. Thermodynamic parameters of DQL-HSA binding systems at different temperatures.

\begin{tabular}{|c|c|c|c|c|c|c|}
\hline Compound & $T(\mathbf{K})$ & $K_{a}\left(\times 10^{4} M^{-1}\right)$ & $R^{\text {a }}$ & $\Delta H\left(\mathrm{~kJ} \mathrm{~mol}^{-1}\right)$ & $\Delta G\left(\mathrm{~kJ} \mathrm{~mol}^{-1}\right)$ & $\Delta S\left(\mathrm{Jmol}^{-1} \mathrm{~K}^{-1}\right)$ \\
\hline \multirow[t]{4}{*}{$\mathbf{R}=\mathbf{H}$} & 298 & 2.16 & 0.99949 & & -24.72 & \\
\hline & 307 & 2.34 & 0.99969 & 7.14 & -25.68 & 106.92 \\
\hline & 316 & 2.54 & 0.99963 & & -26.65 & \\
\hline & 298 & 2.64 & 0.99967 & & -25.22 & \\
\hline \multirow[t]{3}{*}{$\mathbf{R}=\mathbf{F}$} & 307 & 2.86 & 0.99972 & 7.60 & -26.21 & 110.13 \\
\hline & 316 & 3.09 & 0.99981 & & -27.20 & \\
\hline & 298 & 3.44 & 0.99982 & & -25.99 & \\
\hline \multirow[t]{3}{*}{$\mathbf{R}=\mathbf{C l}$} & 307 & 3.92 & 0.99994 & 10.32 & -27.08 & 121.84 \\
\hline & 316 & 4.36 & 0.99995 & & -28.18 & \\
\hline & 298 & 4.37 & 0.99973 & & -26.47 & \\
\hline \multirow[t]{3}{*}{$\mathbf{R}=\mathbf{B r}$} & 307 & 4.63 & 0.99990 & 5.07 & -27.32 & 105.83 \\
\hline & 316 & 4.91 & 0.99997 & & -28.37 & \\
\hline & 298 & 7.21 & 0.99997 & & -26.37 & \\
\hline \multirow[t]{2}{*}{$\mathbf{R}=\mathbf{I}$} & 307 & 7.45 & 0.99993 & 2.80 & -27.29 & 102.40 \\
\hline & 316 & 7.69 & 0.99995 & & -28.21 & \\
\hline
\end{tabular}

${ }^{\mathrm{a}} \mathrm{R}$ is the correlation coefficient.

Table 3. Binding numbers of DQL to HSA at $298 \mathrm{~K}$.

\begin{tabular}{cccc}
\hline compound & $\mathbf{n}$ & $\boldsymbol{R}^{\mathbf{a}}$ & $\boldsymbol{S D}^{\mathbf{b}}$ \\
\hline $\mathbf{R}=\mathbf{H}$ & 0.99314 & 0.99945 & 0.01088 \\
$\mathbf{R}=\mathbf{F}$ & 0.99313 & 0.99970 & 0.00806 \\
$\mathbf{R}=\mathbf{C l}$ & 1.02389 & 0.99956 & 0.00998 \\
$\mathbf{R}=\mathbf{B r}$ & 1.03725 & 0.99959 & 0.00981 \\
$\mathbf{R}=\mathbf{I}$ & 1.07749 & 0.99953 & 0.01087 \\
\hline
\end{tabular}

${ }^{\mathrm{a}} R$ is the correlation coefficient. ${ }^{\mathrm{b}} S D$ is the standard deviation for the $n$ values.

HSA is a globular protein composed of three homologous $\alpha$-helical domains (I-III), and each domain contains two subdomains (A and B). The principal regions of ligand binding sites on albumin locate in hydrophobic cavities in subdomains IIA and IIIA [28]. For instance, phenylbutazone (PB), flufenamic acid (FA) and digitoxin (Dig) bind to site I (subdomain IIA), site II (subdomain IIIA), and site III [30,31], respectively. So, they were used as the site markers in competitive experiments to identify the binding sites of DQL on HSA. The fluorescence quenching data with the presence of site markers were analyzed using the modified Stern-Volmer Equation, and the values of binding constants listed in Table 4 showed a remarkably decrease after the addition of FA, but relatively small changes after the addition of $\mathrm{PB}$ and Dig. Therefore, DQL mainly bound to HSA in site II (subdomain IIIA).

Table 4. Effects of the site probe on the binding constants of DQL to HSA.

\begin{tabular}{ccccc}
\hline Compound & Site marker & $\boldsymbol{K}_{\boldsymbol{a}}\left(\times \mathbf{1 0}^{\mathbf{4}} \mathbf{M}^{-\mathbf{1}}\right)$ & $\boldsymbol{R}^{\mathbf{a}}$ & $\boldsymbol{S D}^{\mathbf{b}}$ \\
\hline $\mathbf{R}=\mathbf{H}$ & Blank & 2.16 & 0.99949 & 0.26651 \\
& PB & 1.88 & 0.99962 & 0.27020 \\
& FA & 1.04 & 0.99948 & 0.25962 \\
& Dig & 2.18 & 0.99938 & 0.24163 \\
\hline
\end{tabular}


Table 4. Cont.

\begin{tabular}{ccccc}
\hline Compound & Site marker & $\boldsymbol{K}_{\boldsymbol{a}}\left(\times \mathbf{1 0}^{\mathbf{4}} \mathbf{M}^{\mathbf{1}}\right)$ & $\boldsymbol{R}^{\mathbf{a}}$ & $\boldsymbol{S D}^{\mathbf{b}}$ \\
\hline $\mathbf{R}=\mathbf{F}$ & Blank & 2.64 & 0.99967 & 0.26883 \\
& PB & 1.91 & 0.99816 & 0.49686 \\
& FA & 1.25 & 0.99958 & 0.26440 \\
$\mathbf{R}=\mathbf{C l}$ & Dig & 2.58 & 0.99900 & 0.29079 \\
& Blank & 3.44 & 0.99982 & 0.19463 \\
& PB & 2.88 & 0.99975 & 0.18165 \\
& FA & 1.11 & 0.99986 & 0.19765 \\
$\mathbf{R}=\mathbf{B r}$ & Dig & 3.34 & 0.99974 & 0.15826 \\
& Blank & 4.37 & 0.99973 & 0.13913 \\
& PB & 4.17 & 0.99991 & 0.09116 \\
& FA & 3.56 & 0.99993 & 0.08566 \\
$\mathbf{R}=\mathbf{I}$ & Dig & 4.33 & 0.99958 & 0.15985 \\
& Blank & 7.21 & 0.99997 & 0.04105 \\
& PB & 6.99 & 0.99995 & 0.05614 \\
& FA & 4.62 & 0.99969 & 0.15900 \\
& Dig & 7.28 & 0.99996 & 0.04216 \\
\hline
\end{tabular}

${ }^{\mathrm{a}} R$ is the correlation coefficient. ${ }^{\mathrm{b}} S D$ is the standard deviation for the $K_{a}$ values.

\subsection{Thermodynamic Parameters and Binding Modes}

The interaction forces between ligands and biomolecules include probably electrostatic interactions, multiple hydrogen bonds, van der Waals force, hydrophobic and steric contacts, and so on [32]. Generally, the signs and magnitudes of the thermodynamic parameters enthalpy change $(\Delta H)$ and entropy change $(\Delta S)$ can account for the main forces involved in the binding process. Ross and Subramanian have summarized the thermodynamic law of judging the primary binding driving force of biomacromolecules with drugs as follows: (1) $\Delta H>0$ and $\Delta S>0$ indicate a hydrophobic interaction; (2) $\Delta H<0$ and $\Delta S<0$ suggest that hydrogen bond and van der Waals force are the dominating force; (3) $\Delta H \cong 0$ and $\Delta S>0$ imply that electrostatic interactions are dominant [33].

If the enthalpy change $(\Delta H)$ does not vary significantly in the temperature studied, both the enthalpy change $(\Delta H)$ and the entropy change $(\Delta S)$ can be evaluated from the van't Hoff equation:

$$
\ln K_{\mathrm{a}}=-\Delta H / R T+\Delta S / R
$$

where $K_{\mathrm{a}}$ is analogous to the associative binding constants at the corresponding temperature and $R$ is the gas constant.

To elucidate the interaction between DQL and HSA, the thermodynamic parameters were calculated from the van't Hoff plots (Figure 4). The enthalpy change $(\Delta H)$ was calculated from the slope of the van't Hoff relationship. The free energy change $(\Delta G)$ was then estimated from the following equation:

$$
\Delta G=\Delta H-T \Delta S
$$

As shown in Table 2, the negative signs for free energy $(\Delta G)$ of the DQL-HSA systems indicated that the interaction processes were spontaneous. The signs for $\Delta H$ and $\Delta S$ of the binding reaction were both 
found to be positive, which indicated that the binding was mainly entropy-derived and the enthalpy was unfavorable for it. Thus, the hydrophobic forces played a major role in the binding process of DQL to HSA.

Figure 4. van't Hoff plots for DQL-HSA systems.

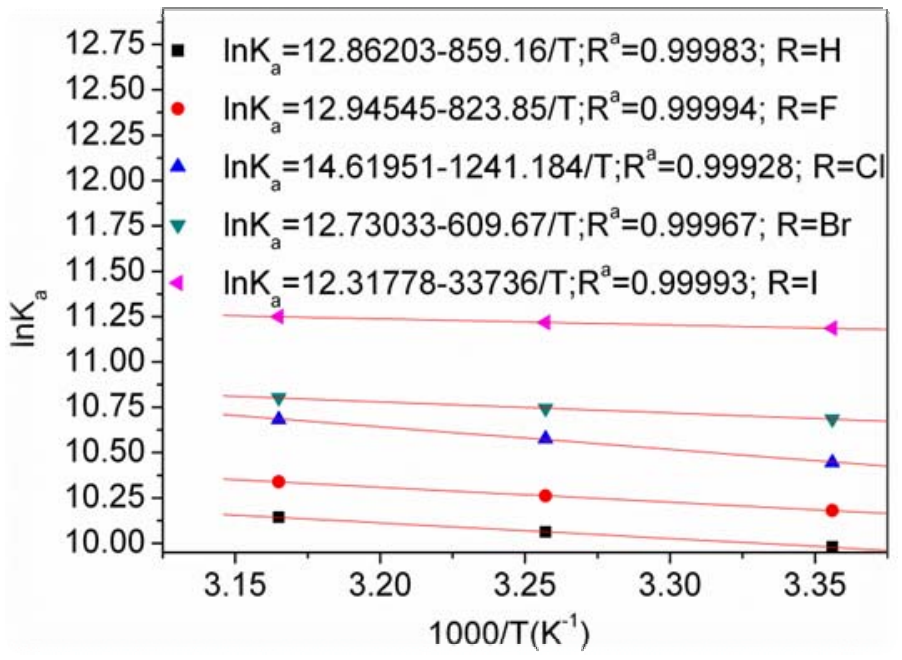

With the use of 2-phenyl-2,3-dihydroquinazolin-4(1H)-one as reference compound, the changes of $\Delta H$ and $\Delta S$ were compared and studied after incorporating halogen atoms in benzene ring. The signs of $\Delta \Delta H$ and $\Delta \Delta S$ listed in Table 5 showed that the binding affinity was enhanced by hydrophobic interaction after incorporating fluorine and chlorine atoms, but by van der Waals force after incorporating bromine and iodine atoms upon on the thermodynamic law summarized by Ross and Subramanian.

Table 5. The values of $\Delta \Delta H$ and $\Delta \Delta S$.

\begin{tabular}{ccc}
\hline Compound & $\boldsymbol{\Delta} \boldsymbol{\Delta} \boldsymbol{H}\left(\mathrm{kJ} \mathrm{mol}^{-\mathbf{1}}\right)$ & $\boldsymbol{\Delta} \boldsymbol{\Delta} \boldsymbol{S}\left(\mathbf{J ~ m o l}^{-\mathbf{1}} \mathbf{K}^{\mathbf{- 1}}\right)$ \\
\hline $\mathbf{R}=\mathbf{F}$ & 0.46 & 3.21 \\
$\mathbf{R}=\mathbf{C l}$ & 3.18 & 14.92 \\
$\mathbf{R}=\mathbf{B r}$ & -2.07 & -1.09 \\
$\mathbf{R}=\mathbf{I}$ & -4.34 & -4.52 \\
\hline
\end{tabular}

In addition, the data at the corresponding temperature in Table 6 displayed the $\Delta G$ changes of interactions of DQL-HSA after incorporating halogen atoms in benzene ring. The values showed that the $\Delta \Delta G$ changed only slightly as the temperature changed, and the negative sign of $\Delta \Delta G$ indicated that incorporation of halogen atoms increased the binding affinity in the DQL-HSA systems. Furthermore, it was interestingly found that the data of $\Delta \Delta G$ decreased regularly with the increasing halogen atomic number.

Table 6. The values of $\Delta \Delta G$ at the corresponding temperature.

\begin{tabular}{|c|c|c|c|c|c|}
\hline & $T(\mathbf{K})$ & $\mathbf{R}=\mathbf{F}$ & $\mathbf{R}=\mathbf{C l}$ & $\mathbf{R}=\mathbf{B r}$ & $\mathbf{R}=\mathbf{I}$ \\
\hline \multirow{3}{*}{$\Delta \Delta G\left(\mathrm{~kJ} \mathrm{~mol}^{-1}\right)$} & 298 & -0.50 & -1.27 & -1.75 & -3.00 \\
\hline & 307 & -0.53 & -1.40 & -1.74 & -2.96 \\
\hline & 316 & -0.55 & -1.53 & -1.72 & -2.91 \\
\hline
\end{tabular}


Moreover, the influence of halogen substituents on drug-protein interaction includes mainly electrostatic, steric and hydrophobic effects. The common parameters of halogen atoms are listed in Table 7 [33]. It can be seen that the atomic radius and hydrophobic parameters increase with the increasing of atomic number of the halogen, while the electronegativity decreases. According to the values of $\Delta \Delta G$ listed in Table 6 , it can be proposed that the steric and hydrophobic effects of halogen atoms played a key role in enhancing the binding affinity of the DQL-HSA systems.

Table 7. The common physicochemical parameters of halogens.

\begin{tabular}{ccccc}
\hline Element & Atomic number & Electronegativity & Atomic radius/A & Hydrophobic parameter \\
\hline F & 9 & 4 & 0.64 & 0.14 \\
$\mathbf{C l}$ & 17 & 3 & 0.99 & 0.71 \\
$\mathbf{B r}$ & 35 & 2.8 & 1.14 & 0.86 \\
$\mathbf{I}$ & 53 & 2.5 & 1.33 & 1.12 \\
\hline
\end{tabular}

\section{Experimental}

\subsection{Apparatus}

Melting points were measured using a Fisher-Johns melting point apparatus (Cole-Parmer Co.) without correcting the thermometer. The NMR spectra were recorded on a Bruker Advance DPX 300 (Bruker, Karlsruhe, Germany) spectrometer using tetramethylsilane (TMS) as internal standard. The IR spectra were recorded on a Bruker Tensor 27 (Bruker Optics GmbH, Ettlingen, Germany) in $\mathrm{KBr}$ pellets in the range 4,000-400 $\mathrm{cm}^{-1}$. Mass spectra were recorded using an HPLC-1100/TOF MS high resolution mass spectrometer (Agilent Technologies. Santa Clara, CA, USA). All fluorescence spectra were measured on a Cray Eclipse fluorescence spectrophotometer (Agilent Technologies, Santa Clara, CA, USA) equipped with a thermostat bath.

\subsection{Reagents}

HSA ( $\geq 99.9$, fatty-acid free), purchased from Sigma-Aldrich (St. Louis, MO, USA), was used without further purification and its molecular weight was assumed to be 66,478. Phenybutazon (PB), fluofenamic acid (FA) and digitoxin (Dig) were of analytical grade, and purchased from the National Institute for Control of Pharmaceutical and Bioproducts (Beijing, China), and the stock solutions were prepared in absolute ethanol. All other chemicals were obtained from commercial sources. Flash column chromatography with silica gel was used to purify the crude products.

\subsection{Fluorescence Titration Experiments}

All HSA solutions were prepared in buffer solution (0.1 M Tris base and $0.1 \mathrm{M} \mathrm{NaCl}$ at $\mathrm{pH} 7.4$ ), and the HSA stock solutions were kept in the dark at $4{ }^{\circ} \mathrm{C}$. The solution $(3.0 \mathrm{~mL})$ containing $1.0 \times 10^{-6} \mathrm{M}$ HSA was titrated by successive additions of $8.0 \times 10^{-4} \mathrm{M}$ ethanol stock solution of DQL (to give a final concentration of $1.333-10.667 \times 10^{-6} \mathrm{M}$ ). Titrations were done manually by using trace syringes, and the fluorescence intensity was measured (excitation at $280 \mathrm{~nm}$ and emission at $337 \mathrm{~nm}$ ). All experiments were conducted at three temperatures $(298,307$, and $316 \mathrm{~K})$. 


\subsection{Site Marker Competitive Experiments}

Binding location studies between DQL and HSA in the presence of three site makers (phenybutazon, fluofenamic acid, digitoxin) were measured using the fluorescence titration methods. The concentration of HSA and site makers were all stabilized at $1.0 \times 10^{-6} \mathrm{M}$. The solution of DQL was then gradually added to the phenybutazon-HSA, fluofenamic acid-HSA, or digitoxin-HSA mixtures, and the fluorescence intensity was recorded (excitation at $280 \mathrm{~nm}$ and emission at $337 \mathrm{~nm}$ ).

\subsection{Synthesis of (un)Substituted Phenyl-2,3-dihydroquinazolin-4(1H)-one Derivatives 3a-3e}

Compound $\mathbf{1}$ and compounds $\mathbf{2 a - 2 e}$ were prepared according to reported methods [35,36]. Their properties were as follows:

2-Amino-5-chlorobenzohydrazide (1): white crystals, yield $85 \%$; m.p. $139.6-140.5{ }^{\circ} \mathrm{C}$; ${ }^{1} \mathrm{H}-\mathrm{NMR}$ $\left(\mathrm{DMSO}-d_{6}\right): \delta 4.38(\mathrm{~d}, 2 \mathrm{H}, J=10.5 \mathrm{~Hz}), 6.47(\mathrm{~s}, 2 \mathrm{H}), 6.71(\mathrm{~d}, 1 \mathrm{H}, J=8.8 \mathrm{~Hz}), 7.15(\mathrm{q}, 1 \mathrm{H}, J=2.5 \mathrm{~Hz}$, $J=8.8 \mathrm{~Hz}), 7.45(\mathrm{~d}, 1 \mathrm{H}, J=2.5 \mathrm{~Hz}), 9.60(\mathrm{~s}, 1 \mathrm{H})$.

3-(Benzylideneamino)-6-chloro-2-phenyl-2,3-dihydroquinazolin-4(1H)-one (2a): light yellow solid, yield 75.3\%; m.p. 193.5-194.5 ${ }^{\circ} \mathrm{C}$; ${ }^{1} \mathrm{H}-\mathrm{NMR}\left(\mathrm{CDCl}_{3}\right): \delta 4.99$ (d, $\left.1 \mathrm{H}, J=2.1 \mathrm{~Hz}\right), 6.27$ (d, $\left.1 \mathrm{H}, J=2.7 \mathrm{~Hz}\right), 6.64$ $(\mathrm{d}, 1 \mathrm{H}, J=8.6 \mathrm{~Hz}), 7.23(\mathrm{~d}, 1 \mathrm{H}, J=2.5 \mathrm{~Hz}), 7.26-7.44(\mathrm{~m}, 8 \mathrm{H}), 7.62(\mathrm{~m}, 2 \mathrm{H}), 7.92(\mathrm{~d}, 1 \mathrm{H}, J=2.4 \mathrm{~Hz})$, $9.18(\mathrm{~s}, 1 \mathrm{H})$.

3-(4-Fluorobenzylideneamino)-6-chloro-2-(4-fluorophenyl)-2,3-dihydroquinazolin-4(1H)-one (2b): white solid, yield 80.3\%; m.p. 217.2-218.4 ${ }^{\circ} \mathrm{C} ;{ }^{1} \mathrm{H}-\mathrm{NMR}\left(\mathrm{CDCl}_{3}\right): \delta 4.95(\mathrm{~d}, 1 \mathrm{H}, J=1.8 \mathrm{~Hz}), 6.23(\mathrm{~d}, 1 \mathrm{H}$, $J=2.6 \mathrm{~Hz}), 6.66(\mathrm{~d}, 1 \mathrm{H}, J=8.6 \mathrm{~Hz}), 6.99-7.60(\mathrm{~m}, 9 \mathrm{H}), 7.90(\mathrm{~d}, 1 \mathrm{H}, J=2.5 \mathrm{~Hz}), 9.16(\mathrm{~s}, 1 \mathrm{H})$.

3-(4-Chlorobenzylideneamino)-6-chloro-2-(4-chlorophenyl)-2,3-dihydroquinazolin-4 $(1 \mathrm{H})$-one (2c): light yellow solid, yield 76.4\%; m.p. 208.2-209.4 ${ }^{\circ} \mathrm{C}$; ${ }^{1} \mathrm{H}-\mathrm{NMR}$ : $\left(\mathrm{CDCl}_{3}\right) \delta 4.96(\mathrm{~d}, 1 \mathrm{H}, J=2.6 \mathrm{~Hz}), 6.22$ $(\mathrm{d}, 1 \mathrm{H}, J=2.9 \mathrm{~Hz}), 6.67(\mathrm{~d}, 1 \mathrm{H}, J=8.6 \mathrm{~Hz}), 7.26-7.36(\mathrm{~m}, 7 \mathrm{H}), 7.55(\mathrm{~m}, 2 \mathrm{H}), 7.90(\mathrm{~d}, 1 \mathrm{H}, J=2.5 \mathrm{~Hz})$, $9.22(\mathrm{~s}, 1 \mathrm{H})$.

3-(4-Bromobenzylideneamino)-6-chloro-2-(4-bromophenyl)-2,3-dihydroquinazolin-4(1H)-one (2d): light yellow solid, yield 72.5\%; m.p. 205.6-206.9 ${ }^{\circ} \mathrm{C} ;{ }^{1} \mathrm{H}-\mathrm{NMR}:\left(\mathrm{CDCl}_{3}\right) \delta 4.96(\mathrm{~s}, 1 \mathrm{H}), 6.20(\mathrm{~d}, 1 \mathrm{H}$, $J=2.3 \mathrm{~Hz}), 6.67$ (d, 1H, $J=8.6 \mathrm{~Hz}), 7.26-7.52(\mathrm{~m}, 9 \mathrm{H}), 7.89$ (d, 1H, $J=2.4 \mathrm{~Hz}), 9.23(\mathrm{~s}, 1 \mathrm{H})$.

3-(4-Iodobenzylideneamino)-6-chloro-2-(4-iodophenyl)-2,3-dihydroquinazolin-4(1H)-one (2e): yellow solid, yield 67.5\%; m.p. 191.6-192.9 ${ }^{\circ} \mathrm{C} ;{ }^{1} \mathrm{H}-\mathrm{NMR}$ : $\left(\mathrm{CDCl}_{3}\right) \delta 5.02(\mathrm{~d}, 1 \mathrm{H}, J=2.8 \mathrm{~Hz}), 6.18(\mathrm{~d}, 1 \mathrm{H}$, $J=2.9 \mathrm{~Hz}), 6.66(\mathrm{~d}, 1 \mathrm{H}, J=8.6 \mathrm{~Hz}), 7.14-7.69(\mathrm{~m}, 9 \mathrm{H}), 7.88(\mathrm{~d}, 1 \mathrm{H}, J=2.5 \mathrm{~Hz}), 9.18(\mathrm{~s}, 1 \mathrm{H})$.

For the preparation of compounds $\mathbf{3 a}-\mathbf{e}$, the corresponding compound $\mathbf{2}(3 \mathrm{mmol})$ in anhydrous tetrahydrofuran $(30 \mathrm{~mL})$ was cooled to $0{ }^{\circ} \mathrm{C}$ with an ice bath, and sodium hydride $(3.6 \mathrm{mmol})$ was added. The mixture was stirred for $0.5 \mathrm{~h}$ at $0{ }^{\circ} \mathrm{C}$ followed by another $1.0 \mathrm{~h}$ at room temperature. tert-Butylacetyl chloride $(3.6 \mathrm{mmol})$ in anhydrous tetrahydrofuran $(5 \mathrm{~mL})$ was added slowly at $0{ }^{\circ} \mathrm{C}$ in $0.5 \mathrm{~h}$, and then the mixture was stirred again at room temperature overnight. The solvent was removed 
under vacuum, and the residue was then purified by flash chromatography using hexane and ethyl acetate $(V / V=6: 1)$ as the eluent to obtain the title compounds.

3-(Benzylideneamino)-6-chloro-1-(3,3-dimethylbutanoyl)-2-phenyl-2,3-dihydroquinazolin-4(1H)-one (3a): white solid, yield 49.5\%; m.p. 149.5-150.8 ${ }^{\circ} \mathrm{C} ;{ }^{1} \mathrm{H}-\mathrm{NMR}$ : (DMSO- $\left.d_{6}\right) \delta 0.97(\mathrm{~s}, 9 \mathrm{H}), 2.70(\mathrm{~s}, 2 \mathrm{H}), 7.18$ (s, 1H), 7.26-7.33 (m, 5H), 7.45-7.63 (m, 5H), 7.78-7.84 (m, 4H), 9.19 (s, 1H); ${ }^{13} \mathrm{C}-\mathrm{NMR}:\left(\mathrm{CDCl}_{3}\right)$ $\delta 29.82,32.28,45.20,71.23,126.03,126.49,127.94,128.50,128.50,128.75,130.84,131.94,132.60$, 134.28, 135.98, 136.13, 152.11, 159.26, 171.21; IR ( $\left.\mathrm{v} \mathrm{cm}^{-1}\right): 2,959.59,1,686.92,1,663.16,1,479.55$, $1,460.12,1,422.33,1,367.15,1,278.13,1,228.41,1,182.76,1,147.96,960.37,828.46,762.81,747.66$, 695.41, 546.30; HRMS: $m / z$ calc for $\mathrm{C}_{27} \mathrm{H}_{26} \mathrm{ClN}_{3} \mathrm{O}_{2}(\mathrm{M}+\mathrm{H})^{+} 460.1714$, found 460.1776 .

3-(4-Fluorobenzylideneamino)-6-chloro-1-(3,3-dimethylbutanoyl)-2-(4-fluorophenyl)-2,3-dihydroquin azolin-4 (1H)-one (3b): white solid, yield 55.6\%; m.p. $117.8-118.9{ }^{\circ} \mathrm{C} ;{ }^{1} \mathrm{H}-\mathrm{NMR}$ : (DMSO- $\left.d_{6}\right) \delta 0.96(\mathrm{~s}$, $9 \mathrm{H}), 2.69(\mathrm{~s}, 2 \mathrm{H}), 7.14(\mathrm{t}, 2 \mathrm{H}, J=8.8 \mathrm{~Hz}), 7.22(\mathrm{~d}, 1 \mathrm{H}, J=5.2 \mathrm{~Hz}), 7.24(\mathrm{~d}, 1 \mathrm{H}, J=5.6 \mathrm{~Hz}), 7.32(\mathrm{t}, 2 \mathrm{H}$, $J=8.8 \mathrm{~Hz}), 7.64(\mathrm{~d}, 2 \mathrm{H}, J=1.3 \mathrm{~Hz}), 7.73(\mathrm{~s}, 1 \mathrm{H}), 7.82(\mathrm{t}, 2 \mathrm{H}, J=1.3 \mathrm{~Hz}), 7.86-7.91(\mathrm{~m}, 1 \mathrm{H}), 9.19$ (s, $1 \mathrm{H}) ;{ }^{13} \mathrm{C}-\mathrm{NMR}:\left(\mathrm{CDCl}_{3}\right) \delta 29.75,32.33,45.22,71.31,115.68,115.97,125.91,127.90,128.55,129.88$, $130.43,131.98,132.02,132.14,132.78,135.81,152.35,159.22,161.04,162.76,164.33,166.10$, 171.25; IR $\left(\mathrm{v} \mathrm{cm}^{-1}\right): 2,955.44,1,677.13,1,603.96,1,509.25,1,486.06,1,428.02,1,358.71,1,271.37$, 1,232.26, 1,180.33, 1,149.41, 1,092.64, 926.36, 837.29, 793.05, 713.61, 576.78, 539.42, 502.58, 456.96; HRMS: $m / z$ calc for $\mathrm{C}_{27} \mathrm{H}_{24} \mathrm{ClF}_{2} \mathrm{~N}_{3} \mathrm{O}_{2}(\mathrm{M}+\mathrm{H})^{+} 496.1525$, found 496.1586 .

3-(4-Chlorobenzylideneamino)-6-chloro-1-(3,3-dimethylbutanoyl)-2-(4-chlorophenyl)-2,3-dihydroquin azolin-4(1H)-one $(3 \mathrm{c})$ : white solid, yield 57.8\%; m.p. 163.4-164.3 ${ }^{\circ} \mathrm{C} ;{ }^{1} \mathrm{H}-\mathrm{NMR}$ : (DMSO- $\left.d_{6}\right) \delta 0.96$ (s, $9 \mathrm{H}), 2.68(\mathrm{~s}, 2 \mathrm{H}), 7.18(\mathrm{~s}, 1 \mathrm{H}), 7.21(\mathrm{~s}, 1 \mathrm{H}), 7.38(\mathrm{~m}, 2 \mathrm{H}), 7.54(\mathrm{~d}, 2 \mathrm{H}, J=1.8 \mathrm{~Hz}), 7.56(\mathrm{~d}, 2 \mathrm{H}$, $J=1.8 \mathrm{~Hz}), 7.64(\mathrm{~d}, 1 \mathrm{H}, J=1.9 \mathrm{~Hz}), 7.82(\mathrm{~m}, 2 \mathrm{H}), 7.85(\mathrm{~d}, 1 \mathrm{H}, J=1.9 \mathrm{~Hz}), 9.16(\mathrm{~s}, 1 \mathrm{H}) ;{ }^{13} \mathrm{C}-\mathrm{NMR}:\left(\mathrm{CDCl}_{3}\right)$ $\delta 29.77,32.37,45.22,71.14,125.90,127.48,129.05,132.28,132.74,132.92,134.77,135.79,136.97$, 152.12, 159.32, 171.30; IR $\left(\mathrm{v} \mathrm{cm}^{-1}\right): 2,957.40,1,668.64,1,598.98,1,481.55,1,424.16,1,360.19$, 1,307.77, 1,267.14, 1,229.15, 1,174.66, 1,144.17, 1,115.53, 1,090.91, 1,014.64, 865.96, 831.56, 792.32, 703.01, 572.44; HRMS: $m / z$ calc for $\mathrm{C}_{27} \mathrm{H}_{24} \mathrm{Cl}_{3} \mathrm{~N}_{3} \mathrm{O}_{2}(\mathrm{M}+\mathrm{H})^{+}$528.0934, found 528.0950.

3-(4-Bromobenzylideneamino)-6-chloro-1-(3,3-dimethylbutanoyl)-2-(4-bromophenyl)-2,3-dihydroquin azolin-4(1H)-one (3d): white solid, yield 53.8\%; m.p. 186.5-187.5 ${ }^{\circ} \mathrm{C} ;{ }^{1} \mathrm{H}-\mathrm{NMR}$ : (DMSO- $\left.d_{6}\right) \delta 0.95$ (s, 9H), $2.66(\mathrm{~s}, 2 \mathrm{H}), 7.11(\mathrm{~s}, 1 \mathrm{H}), 7.13(\mathrm{~s}, 1 \mathrm{H}), 7.51(\mathrm{~d}, 2 \mathrm{H}, J=8.6 \mathrm{~Hz}), 7.64(\mathrm{~d}, 2 \mathrm{H}, J=1.8 \mathrm{~Hz}), 7.67$ (d, $2 \mathrm{H}, J=1.7 \mathrm{~Hz}), 7.69(\mathrm{~s}, 1 \mathrm{H}), 7.76(\mathrm{~d}, 2 \mathrm{H}, 8.6 \mathrm{~Hz}), 7.82(\mathrm{~d}, 1 \mathrm{H}, J=1.0 \mathrm{~Hz}), 9.14(\mathrm{~s}, 1 \mathrm{H})$; ${ }^{13} \mathrm{C}-\mathrm{NMR}$ : $\left(\mathrm{CDCl}_{3}\right) \delta 29.74,32.33,45.17,71.16,122.89,125.35,125.80,127.74,128.60,129.26,131.95,132.25$, 132.91, 133.14, 135.30, 135.74, 152.11, 159.28, 171.25; IR $\left(\mathrm{v} \mathrm{cm}^{-1}\right): 2,956.63,1,668.10,1,591.76$, 1,482.93, 1,431.24, 1,358.21, 1,312.99, 1,269.06, 1,227.36, 1,180.66, 1,149.50, 1,069.88, 1,010.18, 883.59, 820.18, 791.31, 764.64, 717.22, 544.36, 519.33; HRMS: $m / z$ calc for $\mathrm{C}_{27} \mathrm{H}_{24} \mathrm{Br}_{2} \mathrm{Cl} \mathrm{N}_{3} \mathrm{O}_{2}$ $(\mathrm{M}+\mathrm{H})^{+}$615.9924, found 615.9990 .

3-(4-Iodobenzylideneamino)-6-chloro-1-(3,3-dimethylbutanoyl)-2-(4-iodophenyl)-2,3-dihydroquinazol in-4(1H)-one (3e): white solid, yield 50.9\%; m.p. 192.4-193.5 ${ }^{\circ} \mathrm{C} ;{ }^{1} \mathrm{H}-\mathrm{NMR}$ : (DMSO- $\left.d_{6}\right) \delta 0.95(\mathrm{~s}, 9 \mathrm{H})$, $2.67(\mathrm{~s}, 2 \mathrm{H}), 6.95(\mathrm{~s}, 1 \mathrm{H}), 6.98(\mathrm{~s}, 1 \mathrm{H}), 7.60(\mathrm{~d}, 2 \mathrm{H}, J=8.5 \mathrm{~Hz}), 7.63(\mathrm{~d}, 2 \mathrm{H}, J=2.3 \mathrm{~Hz}), 7.67$ (d, 2H, 
$J=8.5 \mathrm{~Hz}), 7.82(\mathrm{~d}, 2 \mathrm{H}, J=1.9 \mathrm{~Hz}), 7.84(\mathrm{~s}, 1 \mathrm{H}), 7.87(\mathrm{~s}, 1 \mathrm{H}), 9.08(\mathrm{~s}, 1 \mathrm{H}) ;{ }^{13} \mathrm{C}-\mathrm{NMR}:\left(\mathrm{CDCl}_{3}\right) \delta 29.76$, 32.36, 45.18, 71.04, 94.68, 97.52, 125.86, 127.92, 128.64, 129.32, 133.73, 135.75, 135.99, 137.93, 152.20, 159.31, 171.28; IR ( $\left.\mathrm{v} \mathrm{cm}^{-1}\right): 2,953.57,1,668.98,1,586.91,1,482.06,1,428.98,1,358.31$, 1,313.50, 1,268.89, 1,227.89, 1,182.93, 1,148.67, 1,058.37, 1,006.36, 883.24, 861.31, 813.70, 789.17, 764.52, 713.54, 516.49; HRMS: $m / z$ calc for $\mathrm{C}_{27} \mathrm{H}_{24} \mathrm{ClI}_{2} \mathrm{~N}_{3} \mathrm{O}_{2}(\mathrm{M}+\mathrm{H})^{+}$711.9646, found 711.9712 .

\section{Conclusions}

In this paper, the interactions of five DQLs with HSA have been studied by fluorescence spectroscopy. The experimental results suggested that DQL could bind to HSA through a static quenching procedure in the site II (subdomain IIIA). The bindings of DQL to HSA were found to be spontaneous and hydrophobicity played a major role in the interactions. The studies of the impact of halogen substituents on the DQL-HSA interactions showed that substitution by halogen atoms in the benzene ring could enhance the binding affinity through the steric and hydrophobic effects; specifically, substitution by fluorine and chlorine atoms enhanced the binding affinity by hydrophobic interaction, while substitution by bromine and iodine atoms enhanced the binding affinity by van der Waals force. Furthermore, the values of $\Delta \Delta G$ provide a quantitative understanding of halogen substituent effect on DQL-HSA interactions. This study is expected to provide some valuable information for the further research in the rational design of this series of compounds. As the functions of the same substituent in aromatic compounds are relative consistent and stable, we believe the obtained results about halogen substituent effect will also provide some valuable information for guiding the modification of other lead compounds containing benzene rings.

\section{Supplementary Materials}

Supplementary materials can be accessed at: http://www.mdpi.com/1420-3049/17/2/2000/s1.

\section{Acknowledgement}

This work was supported by the National Natural Science Foundation of China (NNSFC) (No. 20972186 and 21172256), the National Basic Research Program of China (No. 2010CB126104) and Demonstration of R \& D and Industrialization of Application of the Core Reagent and Intermediate for Scientific Research (No. 2009BAK61B04).

\section{References and Notes}

1. Rohacova, J.; Marin, M.L.; Miranda, A. Complexes between fluorescent cholic acid derivatives and human serum albumin. a photophysical approach to investigate the binding behavior. $J$. Phys. Chem. B 2010, 114, 4710-4716.

2. Kandagal, P.B.; Ashoka, S.; Seetharamappa, J.; Shaikh, S.M.T.; Jadegoud, Y.; Ijare, O.B. Study of the interaction of an anticancer drug with human and bovine serum albumin: Spectroscopic approach. J. Pharm. Biomed. Anal. 2006, 41, 393-399.

3. Li, D.J.; Ji, B.M.; Sun, H.R. Probing the binding of 8-acetyl-7-hydroxycoumarin to human serum albumin by spectroscopic methods and molecular modeling. Spectrochim. Acta Part A 2009, 73, $35-40$. 
4. Boli, A.; Marino, M.; Rimbach, G.; Fanali, G.; Fasano, M.; Ascenzi, P. Flavonoid binding to human serum albumin. Biochem. Biophys. Res. Commun. 2010, 398, 444-449.

5. Cui, F.L.; Fan, J.; Li, J.P.; Hu, Z.D. Interactions between1-benzoyl-4-p-chlorophenyl thiosemicarbazide and serum albumin: Investigation by fluorescence spectroscopy. Bioorg. Med. Chem. 2004, 12, $151-157$.

6. Gao, H.; Lei, L.D.; Liu, J.Q.; Kong, Q.; Chen, X.G.; Hu, Z.D. The study on the interaction between human albumin and a new reagent with antitumor activity by spectrophotometric methods. J. Photochem. Photobiol. A 2004, 167, 213-221.

7. Wang, T.; Xiang, B.R.; Wang, Y.; Chen, C.Y.; Dong, Y.; Fang, H.S.; Wang, M. Spectroscopic investigation on the binding of bioactive pyridazinone derivative to human serum albumin and molecular modeling. Colloids Surf. B Biointerfaces 2008, 65, 113-119.

8. Gao, W.H.; Li, N.N.; Chen, G.P.; Xu, Y.P.; Chen, Y.W.; Hu, S.L.; Hu, Z.D. Binding studies of costunolide and dehydrocostuslactone with HSA by spectroscopy and atomic force microscopy. J. Luminescence 2011, 131, 2063-2071.

9. Soskic, M.; Magnus, V. Binding of ring-substituted indole-3-acetic acids to human serum albumin. Bioorgan. Med. Chem. 2007, 15, 4595-4680.

10. Kumar, S.; Mishra, G.; Singh, G.; Jha, K.K.; Khosa, R.L.; Gupta, S. Quinazolin-4-one: A highly important hetrocycle with diverse biological activities: A review. Der Chimica Sinica. 2011, 2, 36-58.

11. Raghavendra, N.M.; Thampi, P.P.; Gurubasavarajaswamy, P.M. Synthesis and antimicrobial activity of some novel substituted piperazinyl-quinazolin-3(4H)-ones. E-J. Chem. 2008, 5, 23-33.

12. Kumar, P.P.; Rani, B.L.; Sridhar, S. Synthesis and antimicrobial activity of some new schiffbases containing 2-thienyl-3-arylidine substituted-4(3h)-quinazolinone derivatives. Int. J. Pharm. Res. 2011, 3, 90-94.

13. Georgey, H.; Abdel-Gawad, N.; Abbas, S. Synthesis and anticonvulsant activity of some quinazolin-4-(3H)-one Derivatives. Molecules 2008, 13, 2557-2569.

14. Grover, G.; Kini, S.G. Synthesis and evaluation of new quinazolone derivatives of nalidixic acid as potential antibacterial and antifungal agents. Eur. J. Med. Chem. 2006, 41, 256-262.

15. Nanda, A.K.; Ganguli, S.; Chakrabotry, R. Antibacterial activity of some 3-(arylideneamino)Phenylqulinzoline-4(3H)-ones: Synthesis and preliminary QSAR studies. Molecules 2007, 12, 2413-2426.

16. Patil, D.A.; Patil, P.O.; Patil, G.B.; Surana, S.J. Synthesis of 2,3-disubstituted -quinazolin-4(3H)-ones. Mini-Rev. Med. Chem. 2011, 11, 633-641.

17. Sattarova, O.E.; Vizgunova, O.L.; Voronina, E.V. Synthesis and antimicrobial activity of 1,2-diaryland 2,3-diaryl-(2-aryl-3-N-arylamino)-1,2,3,4-tetrahydro-quinazolin-4-ones. Pharm. Chem. J. 2006, $40,15-16$.

18. Gao, X.W.; Cai, X.J.; Yan, K.; Song, B.A.; Gao, L.L.; Chen, Z. Synthesis and antiviral bioactivities of 2-aryl-or2-methyl-3-(substituted-benzalamino)-4(3H)-quinnazolinone derivatives. Molecules 2007, 12, 2621-2642.

19. Lakowicz, J.R. Principles of Fluorescence Spectroscopy, 2nd ed.; Plenum: New York, NY, USA, 1999; p. 239.

20. Lakowicz, J.R. Fluorescence Quenching: Theory and Applications. In Principles of Fluorescence Spectroscopy; Kluwer Academic/Plenum Publishers: New York, NY, USA, 1999; pp. 53-127. 
21. Lakowicz, J.R.; Weber, G. Quenching of fluorescence by oxygen. Probe for structural fluctuations in macromolecules. Biochemistry 1973, 12, 4161-4170.

22. Papadopoulou, A.; Green, R.J.; Frazier, R.A. Interaction of flavonoids with bovine serum albumin: A fluorescence quenching study. J. Agric. Food Chem. 2005, 53, 158-163.

23. Ware, W.R. Oxygen quenching of fluorescence in solution: An experimental study of the diffusion process. J. Phys. Chem. 1962, 66, 455-458.

24. Yu, X.Y.; Liu, R.H.; Yi, R.Q.; Yang, F.X.; Huang, H.W.; Chen, J.; Ji, D.H.; Yang, Y.; Li, X.F.; Yi, P.G. Study of the interaction between N-confused porphyrin and bovine serum albumin by fluorescence spectroscopy. Spectrochim. Acta A 2011, 78, 1329-1335.

25. Tian, F.F.; Jiang, F.L.; Han, X.L.; Xiang, C.; Ge, Y.S.; Li, J.H.; Zhang, Y.; Li, R.; Ding, X.L.; Liu, Y. Synthesis of a novel hydrazone derivative and biophysical studies of its interactions with bovine serum albumin by spectroscopic, electrochemical, and molecular docking methods. J. Phys. Chem. B 2010, 114, 14842-14853.

26. Qin, P.F.; Liu, R.T.; Pan, X.R.; Fang, X.Y.; Mou, Y. Impact of carbon chain length on binding of perfluoroalkyl acids to bovine serum albumin determined by spectroscopic methods. J. Agric. Food Chem. 2010, 58, 5561-5567.

27. Liu, H.; Bao, W.; Ding, H.J.; Jang, J.; Zou, G.L. Binding modes of flavones to human serum albumin: Insights from experimental and computational studies. J. Phys. Chem. B 2010, 114, 12938-12947.

28. Ibrahim, N.; Ibrahim, H.; Kim, S.; Nallet, J.P.; Nepveu, F. Interactions between antimalarial indolone-N-oxide derivatives and human serum albumin. Biomacromolecules 2010, 11, 3341-3351.

29. Carter, D.C.; Ho, J.X. Structure of serum albumin. Adv. Protein. Chem. 1994, 45, 153-203.

30. Sudlow, G.; Birkett, D.J.; Wade, D.N. Further characterization of specific drug binding sites on human serum albumin. Mol. Pharmacol. 1976, 12, 1052-1061.

31. Sjoholm, I.; Ekman, B.; Kober, A.; Ljungstedt-Pahlman, I.; Seiving, B.; Sjodin, T. Binding of drugs to human serum albumin: XI. The specificity of three binding sites as studied with albumin immobilized in microparticles. Mol. Pharmacol. 1979, 16, 767-777.

32. Leckband, D.P. Measuring the forces that control protein interactions. Annu. Rev. Biophys. Biomol. Struct. 2000, 29, 1-13.

33. Ross, D.P.; Subramanian, S. Thermodynamics of protein association reactions: Forces contributing to stability. Biochemistry 1981, 20, 3096-3102.

34. Jiang, F.C. The Principle of Drug Design; Chemical Industry Press: Beijing, China, 2007; pp. 68-71.

35. Sircar, J.C.; Capiris, T.; Kesten, S.J. Pyrazolo [5,1-b]-quinazolin-9-ones: A new series of antiallergic agents. J. Med. Chem. 1981, 24, 735-742.

36. Ferenc, F.; Mario, S.; Kalevi, P. Formation of 1,2-dihydroquinazolin-4(3H)-ones. Reinvestigation of a recently reported 1,3,4-benzotriazepine synthesis. Tetrahedron 1992, 48, 531-538.

Sample Availability: Samples of the compounds are available from authors.

(C) 2012 by the authors; licensee MDPI, Basel, Switzerland. This article is an open access article distributed under the terms and conditions of the Creative Commons Attribution license (http://creativecommons.org/licenses/by/3.0/). 